\title{
Teaching Students the Art of Working with Patients with Cognitive Impairments: A Comparison between the Use of Standardized Patients vs a One-time Clinical Experience
}

\author{
Shaun Varrecchia ${ }^{1}$ and Carol A. Maritz ${ }^{2^{*}}$
}

*Correspondence: c.maritz@usciences.edu

CrossMark

$\leftarrow$ Click for updates

\begin{abstract}
${ }^{1}$ Assistant Professor of Physical Therapy, Samson College of Health Sciences, University of the Sciences, Philadelphia, PA 19104 USA. ${ }^{2}$ Associate Dean and Professor of Physical Therapy, Samson College of Health Sciences, University of the Sciences, Philadelphia, PA 19104 USA.
\end{abstract}

\begin{abstract}
Background: Working with individuals with cognitive impairment can be an uncomfortable experience for students in the health professions. Using a one-time clinical experience to expose them to this population is a common strategy used to increase comfort and improve skills. Unfortunately, relying on outside facilities to provide this experience introduces variability that can negatively affect outcomes.

Objective: The purpose of this study was to compare the outcomes associated with a standardized patient (SP) encounter with a one-time clinical education experience in order to determine the optimal learning opportunity for students.

Methods: Eighty-two DPT students participated in a session where they practiced communication skills and assessment procedures on individuals simulating cognitive impairment. Each group of students performed a brief interview with the SP, administered the Mini-Cog test to screen for cognitive impairment, and completed two performance-based functional outcome measures common in physical therapy. At the completion of the session the SPs stepped out of character and gave the student groups verbal feedback about their performance. Feedback was focused on student communication skills and ability to provide clear instructions while adapting to changes in the SP's cognition.
\end{abstract}

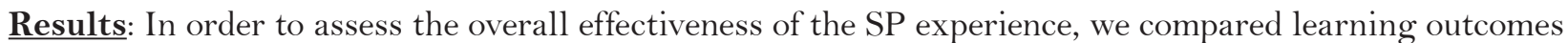
with the one-time clinical experience. The total number of students participating in one of these experiences between 2016 and 2018 was 219. A strong positive trend of improvement is seen between each of the years and between the clinical site and standardized patient experiences. The ability to perform cognitive tests was considerably higher with the SPs than the clinical experiences. Chi-square tests of independence were used to compare students who reported achieving each of the goals of the activity and those who did not across each of the years. Significant relationships were found between achievement of outcomes and the year of participation and type of experience for all five outcomes reported. Effect size surpassed Cohen's definition of "small” (Cramer's V $\geq 0.1$ ) for all five outcomes. Effect size was largest for "performed cognitive tests," with $\boldsymbol{\chi}^{2}(2, \mathrm{~N}=219)=74.24, \mathrm{p}<0.00001$ and $\boldsymbol{\varphi}=0.58$. Student comments regarding each of the experiences was analyzed and compared using qualitative methods. Unique to 2018, was the emergence of the word "feedback." The opportunity to receive feedback was cited in 31 comments in the 2018 SP encounter. Other words emerging in 2018 include "real," "realistic," "convincing," and "accurate".

Conclusion: Overall, there was high level of agreement among the students that the SP experience helped them recognize cognitive impairment and communicate with individuals with cognitive impairment. Students strongly agreed that the SP portrayal was realistic and that the feedback they provided was valuable to their learning. When comparing the SP encounter to the one-time clinical experience, faculty found that the SP experience was more pedagogically sound. Students were actively engaged throughout the entire process especially during the feedback phase.

Keywords: Standardized patients, Communication skills, Formative feedback 


\section{Introduction}

With the graying of the US population, the number of individuals living with cognitive impairment is rising [1]. By 2030 there will be a need for 3.5 million more health care providers. The US has about half the number of providers it currently needs. Training providers to work in the field of geriatrics is critical to meet this demand [2].

It is imperative that health care practitioners are knowledgeable in all areas of geriatric care [3]. In order to educate the next generation of health care providers, competencies have been developed by the different professions to ensure that this training process includes the essential elements needed for practice [4]. The Academy of Geriatric Physical Therapy developed a comprehensive list of competencies that physical therapists must possess upon completion of their training [5]. These competencies focus on communication and psychomotor skills needed to work with this complex patient population.

In addition to the didactic training, physical therapy students take part in several different clinical rotations during their academic training. It is, however, widely agreed that additional course-embedded clinical experiences are also necessary to help link didactic knowledge with clinical skills [6-9]. With the aging population and need for geriatric professionals growing, there has been an increase in the number of students enrolled in most health professions programs across the country. This is especially true in physical therapy, where there is an increased demand for substantially more clinical sites. Unfortunately, there is an insufficient number of clinical sites and instructors to provide students with these clinical experiences $[\mathbf{1 0}, \mathbf{1 1}]$. It is particularly difficult to expose students to patients with cognitive impairment. While some patients are easily brought to campus for the students to work with, this is not a feasible option for those with cognitive impairment due to the sensitive nature of their condition.

An alternative to sending students out to the clinic is the use of standardized patients (SP), laypersons trained to simulate a patient condition to provide students with realistic learning experiences [12]. This provides a safe setting for students to practice their professional communication, collaborate with one another, and perform clinical skills while receiving formative feedback from the SPs. By definition, using standardized patients ensures that all students get a similar experience. It has been found to help improve students' communication skills as well as give them an opportunity to practice their hands-on skills in realistic situations $[14,15]$. In fact, the use of SPs prior to clinical rotations improved the students' perceptions of their preparedness for clinic [16]. It is recommended that students have interactions with SPs early on in their academic program [17].

In the past as part of the didactic course, Geriatric Physical Therapy, students completed a one-time clinical experience where they had the opportunity to work with an individual with cognitive impairment. This Doctor of Physical Therapy
(DPT) program faculty previously worked with several clinics to arrange for these experiences. Despite training the clinical instructors, some students never experienced the opportunity to work with patients who had cognitive impairment. Others never had to opportunity to perform any tests and measures as had been agreed to by the clinical instructors.

To increase our students' exposure to patients with cognitive impairment, a standardized patient session was developed as part of the geriatric physical therapy class. This replaced the previously used one-time clinical experience. Table 1 details the learning objectives for the simulated encounter. Although there is strong evidence to support the use of SPs throughout the training of most health care providers, this DPT program wanted to determine if the use of SPs to portray a patient with cognitive impairment would provide all students with a realistic and authentic experience. The purpose of this study was to compare the outcomes associated with a standardized patient (SP) encounter with a one-time clinical education experience in order to determine the optimal learning opportunity for students.

Table 1. Instructional objectives.

\begin{tabular}{l}
\hline Instructional objectives \\
\hline $\begin{array}{l}\text { 1. Apply knowledge of the physical, psychological, social and } \\
\text { cultural issues of older adults with those who have cognitive } \\
\text { impairment }\end{array}$ \\
\hline 2. Demonstrate effective communication skills when interacting \\
with patients with cognitive impairment \\
3. Perform commonly used functional outcome measures with \\
patients with cognitive impairment \\
$\begin{array}{l}\text { 4. Interpret the findings from the outcome measures relative to falls } \\
\text { risk and safety }\end{array}$
\end{tabular}

\section{Methods and Materials Standardized Patient Encounter Participants}

Eighty-two second year students (34 male; 48 female) in the geriatric physical therapy course participated in this mandatory class session. Students were randomly assigned to 1 of 16 groups of 5-6 participants. Each group was then randomly allocated to participate in a 30-minute encounter with an SP. The University of the Sciences Institutional Review Board approved the study.

Standardized patients were supplied through a local university with a well-established program that is used by many academic programs in the area. The case selected for this experience was a case currently used by this group of SPs (Figure 1). It was modified to fit the outcomes needed for the physical therapy students in a geriatric class. The SPs arrived to campus for a brief training session prior to the student experience. This one-hour training session was provided by the physical therapy course director. SPs were introduced to the outcome measures that the students would have them perform. Agreement was reached with the SPs and the simu- 
You are an older adult who presents for a new patient evaluation at the geriatric physical therapy clinic. Your daughter brought you to the visit but did not come into the exam room with you. You have some underlying cognitive impairment but this is not immediately obvious when others speak to you.

You are very charming, pleasant, and sociable. You are able to give some elements of your history, but you speak in general terms \& defer questions about the details of your diagnoses, medications, and even some elements of the social history. Your clothes are askew and your hair is a little messy.

"My daughter brought me here; she's worried about my memory."

Figure 1. Standardized Patient Case Summary.

lation coordinator regarding the SPs performance on these measures. The focus was on simulating difficulties seen in patients with cognitive impairment including difficulty remembering instructions and the simulation of slow movement patterns. Prior to the event, students were given their group assignment and informed as to which outcome measures their group would be performing. The outcome measures selected were those the students had already learned.

\section{Standardized Patient Intervention}

During their time with the SP, each group of students performed a brief interview with the SP, administered the Mini-Cog ${ }^{\ominus}$ test to screen for cognitive impairment, and completed two performance-based physical therapy functional outcome measures. At the completion of the session the SPs stepped out of character and proceeded to give the student group verbal feedback about their performance. Feedback was focused on their communication skills and ability to provide clear instructions while adapting to changes in the SP's cognition. SPs provided each group of students with verbal formative feedback relative to the encounter. The SP focused their feedback on the group at-large instead of to the individual student.

\section{Quantitative Assessment Measures}

An immediate, paper-based, post-session untimed survey was administered to all students. The questions created for this assessment were grounded in the learning objectives for the experience. Using a 1-4-point Likert-type scale (4=strongly agree, $3=$ agree, 2 disagree, and $1=$ strongly disagree), students responded to 6 questions (Figure 2).

\section{Qualitative Assessment Measures}

The survey also included 2 open-ended questions shown in Figure 2. Students were asked to indicate what they liked best about the experience and also to provide one suggestion to improve the session.

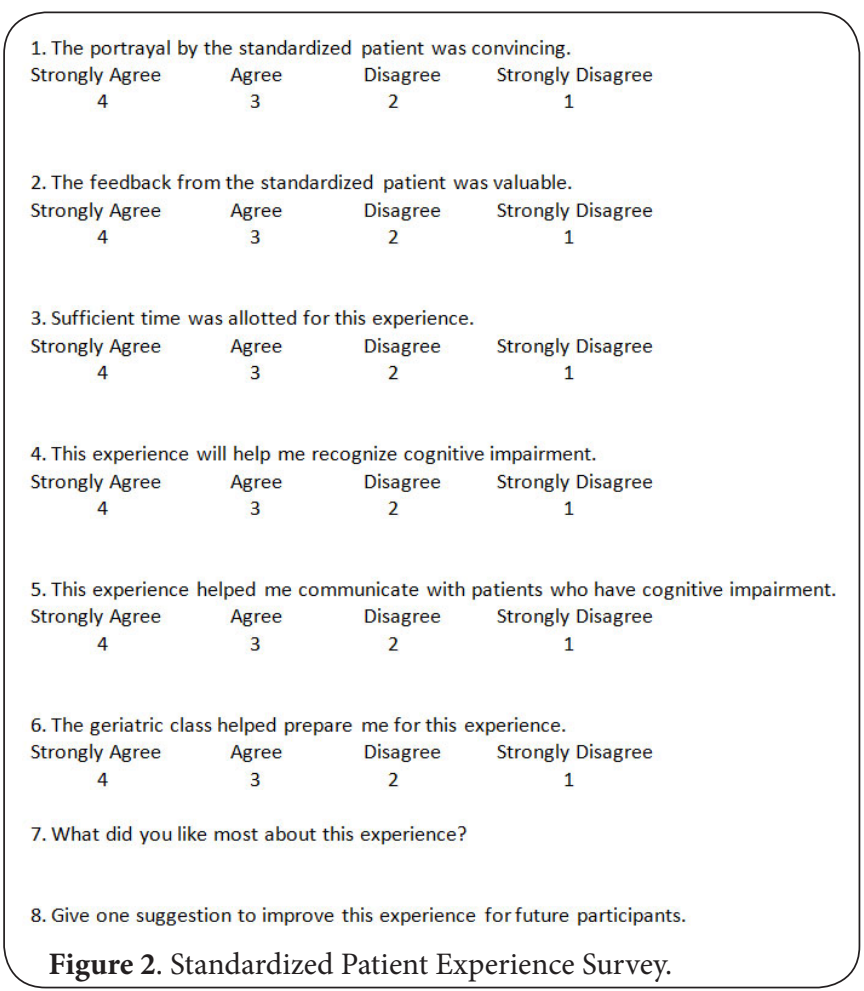

\section{One-time Clinical Experience}

These retrospective data were collected in 2016 and 2017, as part of the one-time clinical experience in the geriatric physical therapy course.

\section{Quantitative Measures}

Following their experience, students were asked to respond to a series of questions. These questions focused on the following areas: experience with an older adult with cognitive impairment, participation in the administration of a cognitive test and a standardized functional outcome measure, experience communicating with a patient with cognitive impairment, and the value of the experience.

\section{Qualitative Measures}

Students were also asked to make comments about the experience in an open-ended format. These comments were to address what they liked best about the experience and suggestions on how to improve it.

\section{Data analysis}

\section{Quantitative Analysis}

Survey data from the 2018 standardized patient experiencewere analyzed and mean scores for each of the six questions were reported. To compare the standardized patient experience to the prior clinical experience, data were analyzed in Excel (version 16.16.10). Five survey questions were determined to be central to our outcomes, "I gained exposure to adults with cognitive impairments," "I was able to participate in the 
administration of a cognitive test," "I was able to participate in the performance of a standardized outcome measure," "I gained practice communicating with an older adult with cognitive impairment," and "Overall, I felt the experience was worthwhile." Frequency count of responses to these questions were determined and analyzed using the chi-square test of independence $(p<0.05)$. Effect size was then calculated using Cramer's V.

\section{Qualitative Analysis}

A thematic approach was used to analyze open-ended questions from the post-session evaluation. Two investigators individually categorized the data and identified key themes and then met to develop a consensus of the themes.

\section{Results}

\section{Standardized Patient Evaluation Survey}

All students strongly agreed or agreed that this experience helped them recognize cognitive impairment (3.78/4) and helped them learn how to communicate with patients who present with cognitive impairment (3.75/4). Regarding the standardized patients, all students agreed or strongly agreed that their portrayal of the patient was convincing (3.94/4) and that the feedback from the SPs was valuable (3.86/4). Students were satisfied with the amount of time allotted for the activity (3.85/4). Finally, students felt that the geriatric class prepared them for this experience (3.64).

There were 2 open-ended questions on the evaluation. The first open-ended prompt asked students what they liked best about the experience, "liked-best." The second open-ended prompt asked students for suggestions for future improvement, "suggestions." 2 major themes were noted related to what the students liked most about this experience. The first was the realistic portrayal of patient with cognitive impairment. The second was the importance of feedback from the SPs (Table 2). Students were also asked to provide one suggestion to improve the session and, overwhelmingly, the response was to have smaller groups in order for the students to have more contact with the SPs. The overwhelming majority of students

Table 2. Student Suggestions.

\begin{tabular}{|c|c|}
\hline \multicolumn{2}{|c|}{ Themes and Supporting Quotations } \\
\hline Smaller sized student groups & $\begin{array}{l}\text { Opportunity to receive more } \\
\text { feedback from SPs }\end{array}$ \\
\hline $\begin{array}{l}\text { "Maybe performing individually } \\
\text { or smaller groups would have } \\
\text { helped us each get a more } \\
\text { hands-on experience" }\end{array}$ & $\begin{array}{l}\text { "Getting more feedback from } \\
\text { the SP" }\end{array}$ \\
\hline $\begin{array}{l}\text { "Smaller groups would allow for } \\
\text { more individualized sessions" }\end{array}$ & $\begin{array}{l}\text { "More feedback that is physical } \\
\text { therapy related" }\end{array}$ \\
\hline "Having fewer people in a group" & $\begin{array}{l}\text { "Extra time for feedback from } \\
\text { the SP" }\end{array}$ \\
\hline $\begin{array}{l}\text { "Smaller groups for more } \\
\text { interaction" }\end{array}$ & $\begin{array}{l}\text { "More opportunities for } \\
\text { feedback from the SP" }\end{array}$ \\
\hline
\end{tabular}

felt that having smaller groups of students would have provided them with a better opportunity for more hands-on practice with the SP.

\section{Comparison of Standardized Patient Encounter with Clinical Experience Quantitative Data}

In order to assess the overall effectiveness of the SP experience, we compared these learning outcomes with the one-time clinical experience. The total number of students participating in one of these experiences between 2016 and 2018 was 219 . Percentage of students reporting agreement with the 5 survey questions is presented in Table 3. For two of the survey questions in 2016, there was one non-response making the number of responses to those questions out of 70 rather than 71. A strong positive trend of improvement was seen between each of the years and between the clinical site and standardized patient experiences. The ability to perform cognitive tests was considerably higher with the SPs than the clinical experiences.

Chi-square tests of independence were used to compare students who reported achieving each of the goals of the activity and those who did not across each of the years. Significant relationships were found between achievement of outcomes and the year of participation and type of experience for all five outcomes reported. Effect size surpassed Cohen's definition of "small" (Cramer's V $\geq 0.1$ ) for all five outcomes. Effect size was largest for "performed cognitive tests," with $\chi^{2}(2, N=219)$ $=74.24, p<0.00001$ and $\varphi=0.58$ (Table 4).

\section{Qualitative Data}

Comparing "liked-best" comments, students overwhelmingly appreciated experiential learning and the opportunity to work with patients. They also showed the students' perceived importance of working in a team to practice communication skills and working with older adults with cognitive impairments. Unique to 2018, was the emergence of the word "feedback." The opportunity to receive feedback was cited in 31 comments in 2018, undoubtedly contributing to the success of the standardized-patient experience over the clinical site visits. Other words emerging in 2018 include "real," "realistic," "convincing," and "accurate" suggesting that indeed the standardized patients were an appropriate substitute for the real thing.

Comparing suggestions across 2016, 2017, and 2018 revealed a more dichotomous set of themes. While the word "patient" appears in all 3 years, students in 2016 and 2017 are frequently suggesting improved patient selection whereas in 2018 students are asking for more or more frequent patient/ standardized-patient encounters. In 2016 and 2017, words such as "preceptor" and "perform" illustrate student suggestions for improved preparation of the preceptors and the opportunity to work in a more hands-on manner with patients. In 2018, however, students frequently recommended changing "nothing." 


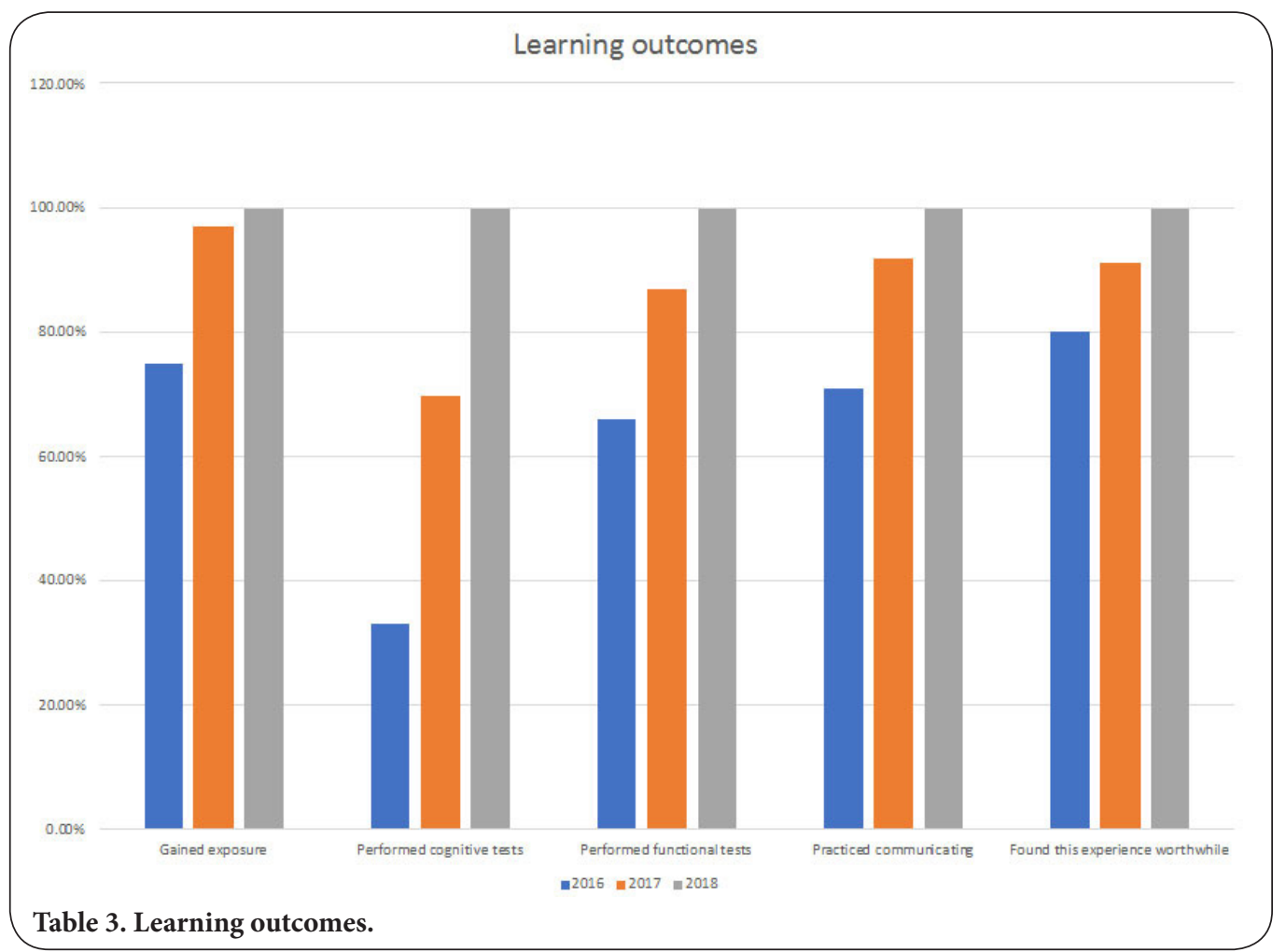

Table 4. chi square.

\begin{tabular}{|c|c|c|c|c|c|}
\hline Outcome & Participants (n) & $\begin{array}{c}\text { Positive } \\
\text { agreement (n) }\end{array}$ & $\begin{array}{c}\text { Negative } \\
\text { agreement }(n)\end{array}$ & $\begin{array}{c}\text { Chi-square test of } \\
\text { independence }\end{array}$ & $\begin{array}{c}\text { Effect size } \\
\text { (Cramer's V) }\end{array}$ \\
\hline \multicolumn{6}{|c|}{ Gained exposure } \\
\hline 2016 & 70 & 53 & \multirow{3}{*}{$\begin{array}{r}17 \\
2 \\
1 \\
\end{array}$} & \multirow{3}{*}{$\begin{array}{l}\chi 2(2)=28.38 \\
p<0.00001\end{array}$} & \multirow[t]{3}{*}{$\boldsymbol{\varphi}=0.36$} \\
\hline 2017 & 68 & 66 & & & \\
\hline 2018 & 80 & 79 & & & \\
\hline \multicolumn{6}{|c|}{ Performed cognitive tests } \\
\hline 2016 & 71 & 24 & \multirow{3}{*}{$\begin{array}{r}47 \\
20 \\
1 \\
\end{array}$} & $\chi^{2}(2)=74.24$ & \multirow[t]{3}{*}{$\varphi=0.58$} \\
\hline 2017 & 68 & 48 & & \multirow{2}{*}{$p<0.00001$} & \\
\hline 2018 & 80 & 79 & & & \\
\hline \multicolumn{6}{|c|}{ Performed functional tests } \\
\hline 2016 & 71 & 47 & \multirow{3}{*}{$\begin{array}{r}24 \\
9 \\
1 \\
\end{array}$} & $\chi^{2}(2)=30.79$ & \multirow[t]{3}{*}{$\varphi=0.37$} \\
\hline 2017 & 68 & 59 & & \multirow{2}{*}{$\begin{array}{l}X<(2)=30.19 \\
p<.00001\end{array}$} & \\
\hline 2018 & 80 & 79 & & & \\
\hline \multicolumn{6}{|c|}{ Practiced communicating } \\
\hline 2016 & 70 & 50 & \multirow{3}{*}{\begin{tabular}{r|}
20 \\
5 \\
1
\end{tabular}} & $\chi^{2}(2)=28.50$ & \multirow[t]{3}{*}{$\boldsymbol{\varphi}=0.36$} \\
\hline 2017 & 68 & 63 & & $p<.00001$ & \\
\hline 2018 & 80 & 79 & & & \\
\hline \multicolumn{6}{|c|}{ Worthwhile experience } \\
\hline 2016 & 71 & 57 & 14 & \multirow{3}{*}{$\begin{array}{l}\chi^{2}(2)=14.87 \\
p=.000592\end{array}$} & \multirow[t]{3}{*}{$\boldsymbol{\varphi}=0.26$} \\
\hline 2017 & 68 & 62 & 6 & & \\
\hline 2018 & 80 & 79 & 1 & & \\
\hline
\end{tabular}

Instead, they recognized the "organized" nature of the event. And in recognizing the "hands-on" nature of the encounter, they advocated for "smaller" groups or "one-on-one" encounters and in a couple of instances implied that they felt the patient felt "bombarded" or "overwhelmed."These comments can be used to punctuate the realistic portrayal by the actor as students extended empathy to a patient that was not, in fact, real.

\section{Discussion}

This one-time hands-on learning activity using standardized 
patients provided a worthwhile educational experience for students in a geriatric physical therapy class. By affording them the opportunity to practice their communication and clinical skills with the SP, students noted increased self-confidence agreeing with previous studies $[16,18,19]$. This session also offered students the opportunity to receive feedback from the standardized patients following the encounter. While formative in nature, $96.5 \%$ students remarked how helpful it was to hear that they said. Moreover, the students expressed how valuable formative feedback from the SPs was to them, consistent with the literature $[15,20,21]$. Faculty were elated to observe how engaged the students were during the feedback session. While receiving feedback from the SPs the students demonstrate active listening skills as noted by their non-verbal communication and attentiveness.

In order to complete this experience, students were required to apply knowledge and skills gained from the didactic portion of this course. Having the students perform psychomotor tasks on the SP enabled them to reflect on their actions and adjust based on the SP's responses. This application sought to bridge classroom learning and clinical practice $[15,20,22,23]$. One student remarked "Having the SP really helped implement what I've been learning in class to working with a patient". All of the students reported having had the opportunity to work with a patient with cognitive impairment in 2018 whereas in 2017 it was $97 \%$ and in 2016, 76\%.

Prior to the SP experience, faculty were concerned that some students may not find engaging with an actor on campus to be an authentic activity. According to the students, they found the SP's portrayal of the patient simulation to be realistic and authentic. This is in keeping with other similar studies $[\mathbf{2 0}, \mathbf{2 4}, \mathbf{2 5}]$. This realistic presentation allowed students to become emotionally engaged with the SPs thereby enabling them to treat them as real patients [24]. Since the SPs were able to present with cognitive impairment in a standardized unvarying manner, overall better outcomes were achieved compared to sending students out to the clinic where there is little to no control. The use of SPs in this one-time experience resulted in students successfully meeting the instructional objectives. Additionally, faculty support using SPs to ensure standardization of clinical experiences compared with random occurrences during traditional clinical experiences. These experiences led to meeting the objectives for this learning activity [13].

For the two years prior to this standardized patient experience, students were sent to different clinical sites where the intention was for them to have the same interaction with patients with cognitive impairment. Frequent criticisms from students relative to the clinical experiences were travel time and cost. Despite the yearly training of the sites to ensure that all students, regardless of the setting, had a similar experience,we were not completely successful. Unfortunately, there were several instances where the students did not have the opportunity to work with a patient that had cognitive impairment. Furthermore, the amount of time spent organizing the clinic visits was substantially greater than the time needed to coordinate the SP experience. The standardized patient experience was held on campus where students were required to perform tests and measures under the supervision of the course instructors. The organization and training of the SPs was handled by the group providing the SPs as part of their service. Some of the literature cites the cost of using an $\mathrm{SP}$ as being too expensive for most programs. The cost per student for this one-time experience was $\$ 12$. The convenience for students was significant as there was no travel involved.

Overall, there was high level of agreement among the students that the SP experience helped them recognize cognitive impairment and communicate with individuals with cognitive impairment. Students strongly agreed that the SP portrayal was realistic and that the feedback they provided was valuable to their learning. When comparing the SP encounter to the one-time clinical experience, we found that the SP experience was more pedagogically sound. Students were actively engaged throughout the entire process especially during the feedback phase.

From the faculty perspective, the use of SPs in this onetime experience resulted in students successfully meeting the instructional objectives. For experiences that occur early in the program, where the attainment of knowledge and skills is primary, faculty support the use of SPs to ensure standardization of clinical experiences compared with random occurrences during traditional clinical experiences. Once students demonstrate understanding of these foundational objectives, they can be progressed to more traditional site-based experiences where application and integration of these skill can be delivered in a more individualized manner.

While extremely positive, the student comments did provide suggestions for how to further improve this experience. Moving forward the goal is to reduce the size of the student groups to allow for greater involvement of students and more focused formative feedback. Additionally, a longer-term goal is to include occupational therapy students to work with the physical therapy students in an interprofessional experience.

\section{Competing interests}

The authors declare that they have no competing interests.

\section{Authors' contributions}

\begin{tabular}{|l|c|c|}
\hline Authors' contributions & VS & CAM \\
\hline Research concept and design & $\checkmark$ & $\checkmark$ \\
\hline Collection and/or assembly of data & $\checkmark$ & $\checkmark$ \\
\hline Data analysis and interpretation & $\checkmark$ & $\checkmark$ \\
\hline Writing the article & $\checkmark$ & $\checkmark$ \\
\hline Critical revision of the article & $\checkmark$ & $\checkmark$ \\
\hline Final approval of article & $\checkmark$ & $\checkmark$ \\
\hline Statistical analysis & $\checkmark$ & $\checkmark$ \\
\hline
\end{tabular}


Publication history

Editor: Mohammad H. Hadadzadeh, Wheeling Jesuit University, USA Received: 05-Dec-2019 Final Revised: 09-Feb-2020

Accepted: 24-Feb-2020 Published: 06-Mar-2020

\section{References}

1. Luck T, Luppa M, Briel S and Riedel-Heller SG. Incidence of mild cognitive impairment: a systematic review. Dement Geriatr Cogn Disord. 2010; 29:164-75. I Article I PubMed

2. Warshaw GA and Bragg EJ. Preparing the health care workforce to care for adults with Alzheimer's disease and related dementias. Health Aff (Millwood). 2014; 33:633-41. I Article | PubMed

3. Mezey M, Mitty E, Burger SG and McCallion P. Healthcare professional training: a comparison of geriatric competencies. J Am Geriatr Soc. 2008; 56:1724-9. | Article | PubMed

4. Charles L, Triscott JA, Dobbs BM and McKay R. Geriatric core competencies for family medicine curriculum and enhanced skills: care of elderly. Can Geriatr J. 2014; 17:53-62. | Article | PubMed Abstract | PubMed FullText

5. Essential Competencies in the Care of Older Adults. J. Phys. Ther. Educ. 2014.

6. McCallum C, Bayliss J, Becker E, Nixon-Cave K, Colgrove Y, KucharskiHoward J, Stern D, Evans K, Strunk V, Wetherbee E, Russell B and Legar T. The Integrated Clinical Education Strategic Initiatives ProjectDevelopment of Parameters to Guide Harmonization in Clinical Education: A Scoping Review. Phys Ther. 2019; 99:147-172. | Article | PubMed

7. E. W. Hakim et al. Application of Educational Theory and Evidence in Support of an Integrated Model of Clinical Education. J. Phys. Ther. Educ. 2017.

8. M. L. Weddle and D. O. Sellheim. Linking the Classroom and the Clinic: A Model of Integrated Clinical Education for First-Year Physical Therapist Students. J. Phys. Ther. Educ. 2017.

9. J. A. Mai, A. Thiele, B. O’Dell, B. Kruse, M. Vaassen and A. Priest. Utilization of an Integrated Clinical Experience in a Physical Therapist Education Program. J. Phys. Ther. Educ. 2017.

10. Casares GS, Bradley KP, Jaffe LE and Lee GP. Impact of the changing health care environment on fieldwork education: perceptions of occupational therapy educators. J Allied Health. 2003; 32:246-51. I PubMed

11. Varland J, Cardell E, Koski J and McFadden M. Factors Influencing Occupational Therapists' Decision to Supervise Fieldwork Students. Occup Ther Health Care. 2017; 31:238-254. | Article I PubMed Abstract | PubMed FullText

12. May W, Park JH and Lee JP. A ten-year review of the literature on the use of standardized patients in teaching and learning: 1996-2005. Med Teach. 2009; 31:487-92. | Article | PubMed

13. Calohan J, Pauli E, Combs T, Creel A, Convoy S and Owen R. Using Simulation in a Psychiatric Mental Health Nurse Practitioner Doctoral Program. J Prof Nurs. 2016; 32:458-462. I Article I PubMed

14. Zraick RI, Allen RM and Johnson SB. The use of standardized patients to teach and test interpersonal and communication skills with students in speech-language pathology. Adv Health Sci Educ Theory Pract. 2003; 8:237-48. | Article | PubMed

15. Goh YS, Selvarajan S, Chng ML, Tan CS and Yobas P. Using standardized patients in enhancing undergraduate students' learning experience in mental health nursing. Nurse Educ Today. 2016; 45:167-72. | Article | PubMed

16. D. D. Gardner et al. Using Standardized Patients as Part of a Preclinical Simulation. Respir. Care Educ. Annu. 2018.

17. L. Cahalin, Lawrence P, Markowski, Alycia, Hickey, Mary and Hayward. A Cardiopulmonary Instructor's Perspective on a Standardized Patient Experience : Implications for Cardiopulmonary Physical Therapy Education. Cardiopulm. Phys. Ther. J. 2011.
18. Hook KM and Pfeiffer CA. Impact of a new curriculum on medical students' interpersonal and interviewing skills. Med Educ. 2007; 41:1549. | Article | PubMed

19. Rickles NM, Tieu P, Myers L, Galal S and Chung V. The impact of a standardized patient program on student learning of communication skills. Am J Pharm Educ. 2009; 73:4. | Article | PubMed Abstract | PubMed FullText

20. Giesbrecht EM, Wener PF and Pereira GM. A mixed methods study of student perceptions of using standardized patients for learning and evaluation. Adv Med Educ Pract. 2014; 5:241-55. I Article I PubMed Abstract I PubMed FullText

21. Vessey JA and Huss K. Using standardized patients in advanced practice nursing education. J Prof Nurs. 2002; 18:29-35. | Article I PubMed

22. Stumbar SE, Minor S and Samuels M. A Prenatal Standardized Patient Experience for Medical Students on Their Family Medicine Clerkship. Fam Med. 2018; 50:376-379. | Article | PubMed

23. Benson JD, Provident I and Szucs KA. An experiential learning lab embedded in a didactic course: outcomes from a pediatric intervention course. Occup Ther Health Care. 2013; 27:46-57. I Article I PubMed

24. Kowitlawakul Y, Chow YL, Salam ZH and Ignacio J. Exploring the use of standardized patients for simulation-based learning in preparing advanced practice nurses. Nurse Educ Today. 2015; 35:894-9. | Article | PubMed

25. L. M. Hayward, B. Blackmer and A. Markowski. Standardized Patients and Communities of Practice: A Realistic Strategy for Integrating the Core Values in a Physical Therapist Education Program. J. Phys. Ther. Educ. 2006.

\section{Citation:}

Varrecchia S and Maritz CA. Teaching Students the Art of Working with Patients with Cognitive Impairments: A Comparison between the Use of Standardized Patients vs a One-time Clinical Experience. Phys Ther Rehabil. 2020; 7:2. http://dx.doi.org/10.7243/2055-2386-7-2 